\title{
Quantum Dots as Global Temperature Measurements
}

\author{
Hirotaka Sakaue ${ }^{1}$, Akihisa Aikawa ${ }^{1}$, Yoshimi Iijima ${ }^{1}$, \\ Takuma Kuriki ${ }^{2}$ and Takeshi Miyazaki² \\ 1 Japan Aerospace Exploration Agency \\ ${ }^{2}$ The University of Electro-Communications \\ Japan
}

\section{Introduction}

ZnS-capped CdSe semiconductor nanocrystals (quantum-dots, QDs) provide size-tunable optical properties. QDs show shifted luminescent peaks due to crystal size. They exhibit strong and stable luminescence with a $50 \%$ quantum yield at room temperature [1]. Walker et al. used QDs as a global temperature probe [2]. They used a polymer support of poly(lauryl methacrylate) to create a global temperature sensor. This type of sensor, called a temperature-sensitive paint (TSP), has been widely used in aerospace measurements [3]. Conventional TSP uses a phosphorescent molecule as a temperature probe. This type of molecule has a relatively wide FWHM (full width at half maximum), which is roughly 100 $\mathrm{nm}$. When applying a QD as a temperature probe, the FWHM is narrower than that of phosphorescent probes and is roughly $40 \mathrm{~nm}$ [1]. A low FWHM will widen the selection of probe molecules to prepare multi-color sensors in the visible wavelength range. In addition, a high quantum yield of QDs can be beneficial as an optical temperature sensing probe to increase the signal-to-noise ratio.

The material properties of polymers change the glass-transition temperature. These temperatures for TSPs are roughly $400 \mathrm{~K}[4,5$, and 6]. To use polymers as a QD support, the resultant TSP can be sprayed on a testing article. However, the measurement range is limited by these temperatures. Even for low temperature measurements, a polymer may show physical defects such as cracks at cryogenic temperatures. In aerospace engineering, anodized aluminum has been applied as a support for pressure probes. The resultant sensor, called anodized-aluminum pressure-sensitive paint, has been used in wind tunnel measurements [7]. With aluminum, which has a melting point of $930 \mathrm{~K}$, as a probe support, the anodized aluminum retains its material properties at cryogenic temperatures as well as at temperatures higher than glass-transition temperatures of TSP polymers. By using anodized aluminum as a support for a temperature sensing probe, a global temperature sensor with a wide range can be created.

TSP gives global temperature information related to its luminescent output. The TSP measurement system consists of a TSP coated model, an image acquisition unit, and an image processing unit (Fig. 1). For image acquisition, an illumination source and a photodetector are required. To separate the illumination and the TSP emission detected by a 
photo-detector, appropriate band-pass filters are placed in front of an illumination and a photo-detector. The image processing unit includes calibration and computation. The calibration relates the luminescent signal to temperatures. Based on these calibrations, luminescent images are converted to a temperature map using a PC.

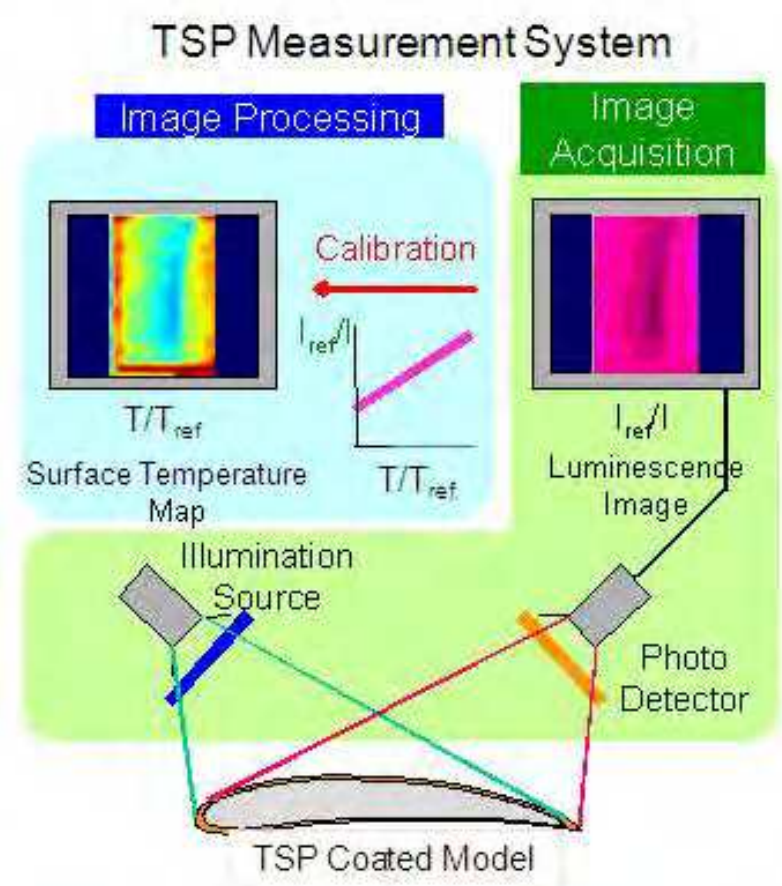

Fig. 1. Schematic of TSP measurement system

In this chapter, the development of a QD-based anodized aluminum temperature sensor is discussed. The temperature sensitivity of this sensor is characterized in the temperature range from $100 \mathrm{~K}$ to $500 \mathrm{~K}$. An application of this sensor as a global temperature measurement is included, which is focused on a hypersonic flow where an aerodynamic heating is a critical issue.

\section{Development of quantum-dot based anodized-aluminum temperature- sensitive paint (AA-TSP)}

\subsection{Materials and dipping deposition method}

A temperature probe of QDs was applied on an anodized-aluminum surface by the dipping deposition method [8]. QDs of birch yellow from Evident Technologies (ED-C11-TOL-0580) were used. These QDs are called $\mathrm{QD}_{\mathrm{BY}}$ in this chapter. The dipping deposition method 
requires a temperature probe of $\mathrm{QD}_{\mathrm{BY}}$, a solvent, and an anodized aluminum coating. The application procedure is schematically shown in Fig. 2. $\mathrm{QD}_{\mathrm{BY}}$ was dissolved in eight different solvents, which varied according to their polarity index (Table 1). A concentration of $15 \mu \mathrm{M}$ was adjusted to create these solutions or mixtures.

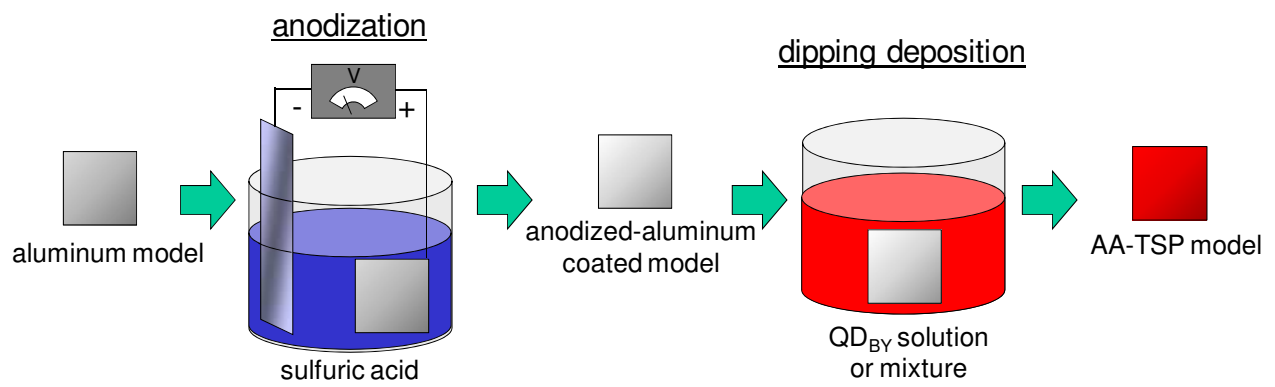

Fig. 2. Schematic description of dipping deposition method

\begin{tabular}{rlc} 
AA-TSP & \multicolumn{1}{c}{ Solvent } & Polarity Index \\
\hline \hline AATSP $_{\text {ind00 }}$ & hexane & 0.1 \\
AATSP $_{\text {ind02 }}$ & toluene & 2.4 \\
AATSP $_{\text {ind03 }}$ & dichloromethane & 3.1 \\
AATSP $_{\text {ind04 }}$ & chloroform & 4.1 \\
AATSP $_{\text {ind05 }}$ & acetone & 5.1 \\
AATSP $_{\text {ind06 }}$ & N,N-dimethylformamide & 6.4 \\
AATSP $_{\text {ind07 }}$ & dimethylsulfoxide & 7.2 \\
AATSP $_{\text {ind10 }}$ & water & 10.2
\end{tabular}

Table 1. List of solvent conditions

Depending on the polarity index of solvents, differences in dissolution can be seen. Solvents with a lower polarity index up to 4.1 could dissolve $\mathrm{QD}_{\mathrm{BY}}$, while solvents with a higher polarity index created mixtures. These are seen in luminescence from the $\mathrm{QD}_{\mathrm{BY}}$ solutions and mixtures (Fig. 3). Luminescent images were acquired using the camera system discussed in section 2.2. Solvents with a lower polarity index up to 4.1 showed relatively bright luminescence, while solvents with a higher polarity index showed dim luminescence or luminescence in spots. The anodized-aluminum coating was dipped in these solutions or mixtures for one hour at room conditions. The AA-TSPs developed were identified by the solvents used, which are listed in Table 1. We coated QD $\mathrm{Q}_{\mathrm{BY}}$ with some of these solutions. Fig. 4 shows luminescent images of AA-TSPs, which were acquired using the camera system discussed in section 2.2. We can see uniform coatings using AATSP ind00, AATSP ind02, $_{\text {, }}$

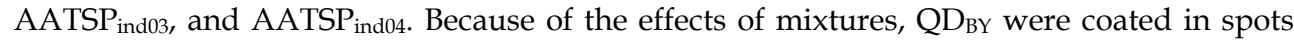

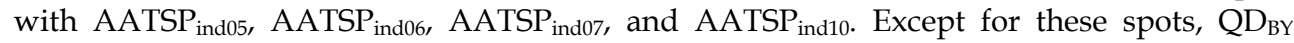
were not coated as shown in the dark luminescent signal in Fig. 4. The signal level was determined from the averaged luminescent signal of each sample. A luminescent signal from a $5-\mathrm{mm}^{2}$ area was averaged. The signal levels were normalized based on the signal of 
AATSP $_{\text {ind04, }}$ which is also shown in Fig. 4. The maximum luminescent signal was obtained

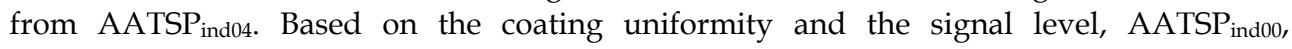
$\mathrm{AATSP}_{\text {ind02, }} \mathrm{AATSP}_{\text {ind03, }}$ and $\mathrm{AATSP}_{\text {ind04 }}$ were selected for temperature calibration.

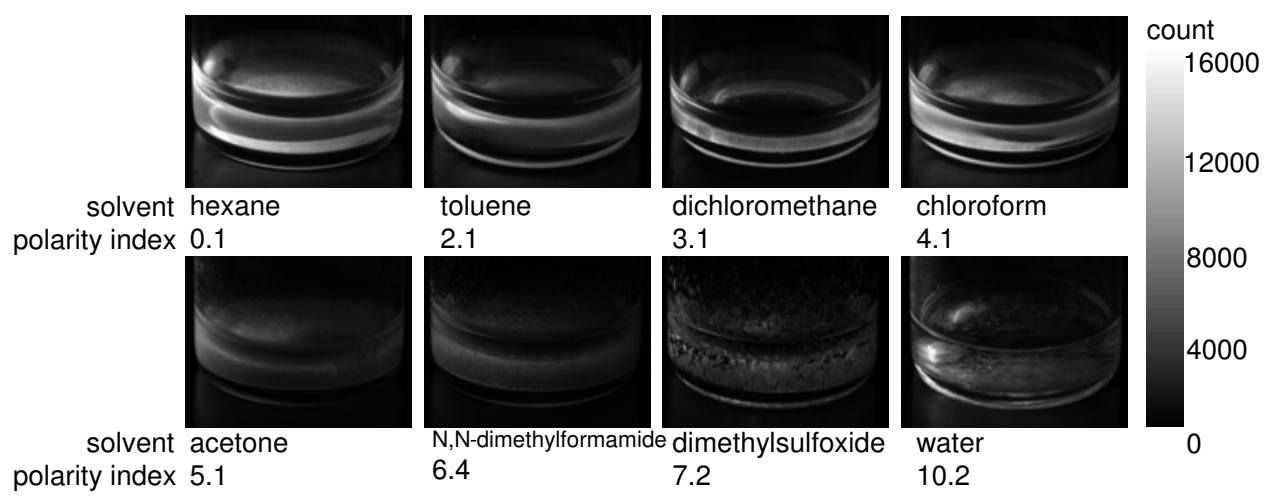

Fig. 3. Luminescence from $\mathrm{QD}_{\mathrm{BY}}$ solutions and mixtures. (Figures obtained from Sakaue et al. [9])

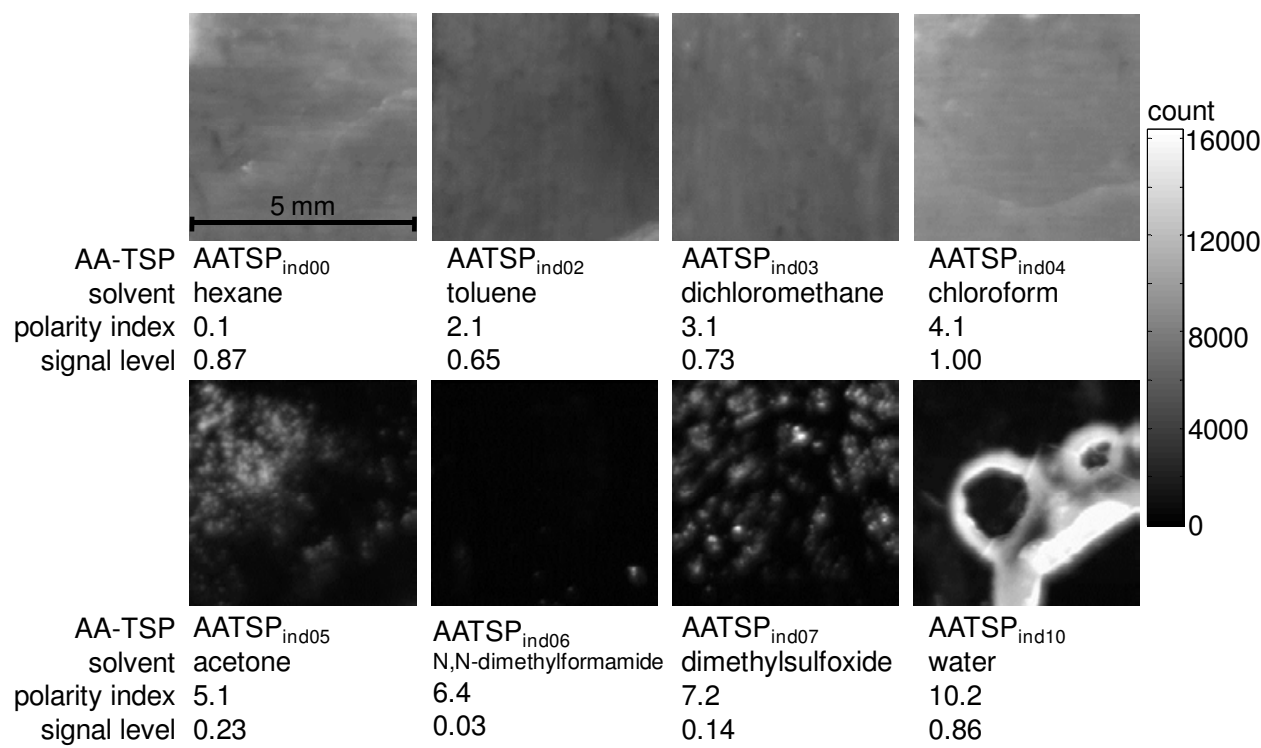

Fig. 4. Luminescent image and signal level of developed AA-TSPs. (Figures obtained from Sakaue et al. [9]) 


\subsection{AA-TSP characterization method}

Fig. 5 schematically describes the calibration setup, which combined a camera system and a spectrometer system. Both systems used a temperature-controlled chamber. The temperature could be controlled from $100 \mathrm{~K}$ to $500 \mathrm{~K}$. The chamber was filled with dry air at $100 \mathrm{kPa}$. An AA-TSP sample was placed on the test section in the chamber. Both systems used a 407-nm laser (NEO ARK, DPS-5001) to illuminate the sample.

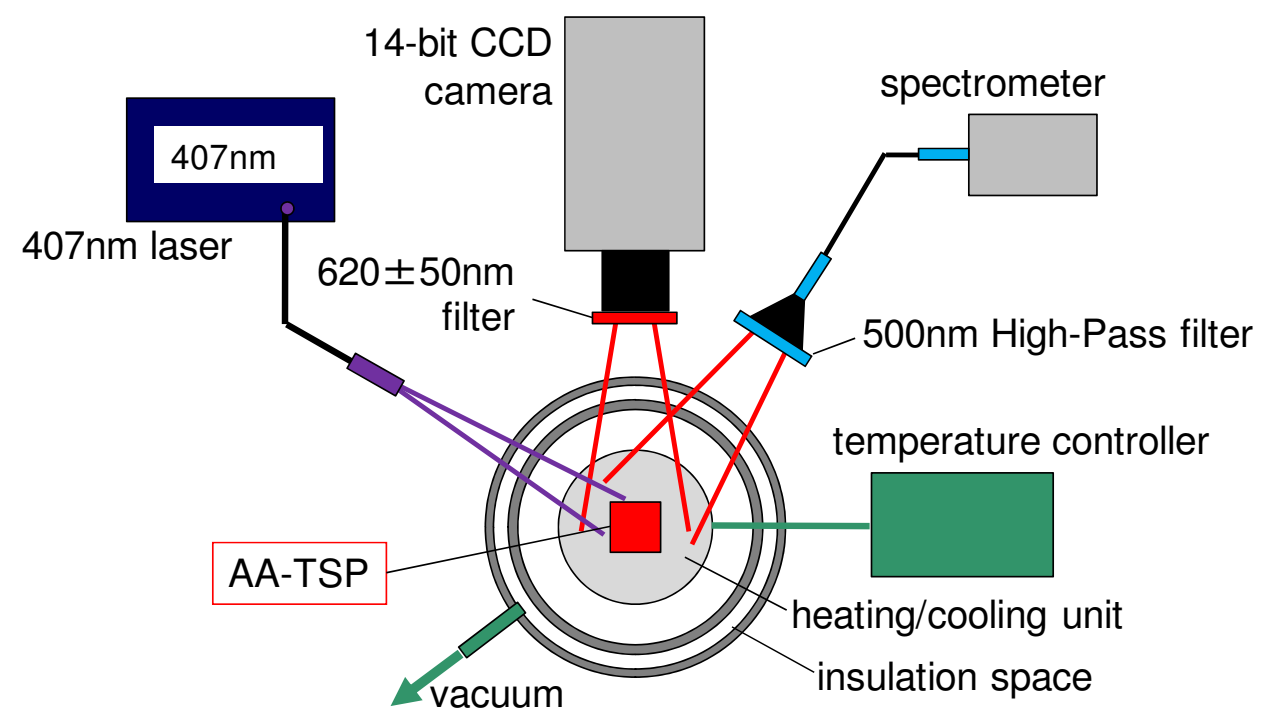

Fig. 5. Schematic of AA-TSP calibration setup

The camera system used a 14-bit CCD camera (Hamamatsu, C4880). A $620 \pm 50 \mathrm{~nm}$ filter was placed in front of the camera lens to acquire only the luminescent signal from AA-TSPs, QD BY solutions, and mixtures. The camera system was used to characterize the signal level and temperature sensitivity. For the camera system, a reference luminescent image, $I_{r e f}$, was obtained. This image was compared with the luminescent image at a given temperature to decouple the non-temperature induced luminescence, such as illumination variation and/or coating non-uniformity. $I_{\text {ref }}$ was used as an image at a reference temperature of $298 \mathrm{~K}$. The spectrometer system used a USB4000 spectrometer from Oceanoptics. It was connected to an optical fiber with a 500-nm high-pass filter in front of the fiber end. This system was used to characterize the luminescent spectrum of the AA-TSPs.

\subsection{Characterization results: Solvent dependency}

Fig. 6 shows the temperature calibrations of selected AA-TSPs obtained from the camera system. The reference temperature was $298 \mathrm{~K}$. The temperature calibrations decreased monotonically with increasing temperature. The temperature calibration of a relatively small temperature range, such as 30 degrees, could be assumed to be linear for engineering applications. The first-order polynomial was fitted to the calibration results. 


$$
\frac{I}{I_{r e f}}=C_{s 0}+C_{s 1} T
$$

Where $c_{s 0}$ and $c_{s 1}$ were calibration constants. The temperature sensitivity, $\delta_{T}$, is defined as the slope of the temperature calibration at the reference temperature, $T_{\text {ref }}$, which is described as the percent change in luminescent signal, $I / I_{\text {ref }}$, over a given temperature in Kelvin.

$$
\delta_{T}=\left.\frac{d\left(I / I_{\text {ref }}\right)}{d T}\right|_{T=T_{\text {ref }}}=C_{s 1}(\% / \mathrm{K})
$$

The $\delta_{T}$ is large if its absolute value is large because a high signal change over a given temperature can be obtained. Based on equations (1) and (2), the $\delta_{T}$ S of selected AA-TSPs was determined: the $\delta_{T} \mathrm{~S}$ are listed in Table 2. It also lists the signal levels of selected AA-

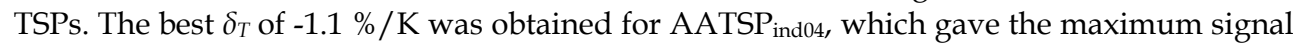
level. Based on these characterizations, using chloroform as a dipping solvent resulted in the application of $\mathrm{QD}_{\mathrm{BY}}$ on the anodized-aluminum coating.

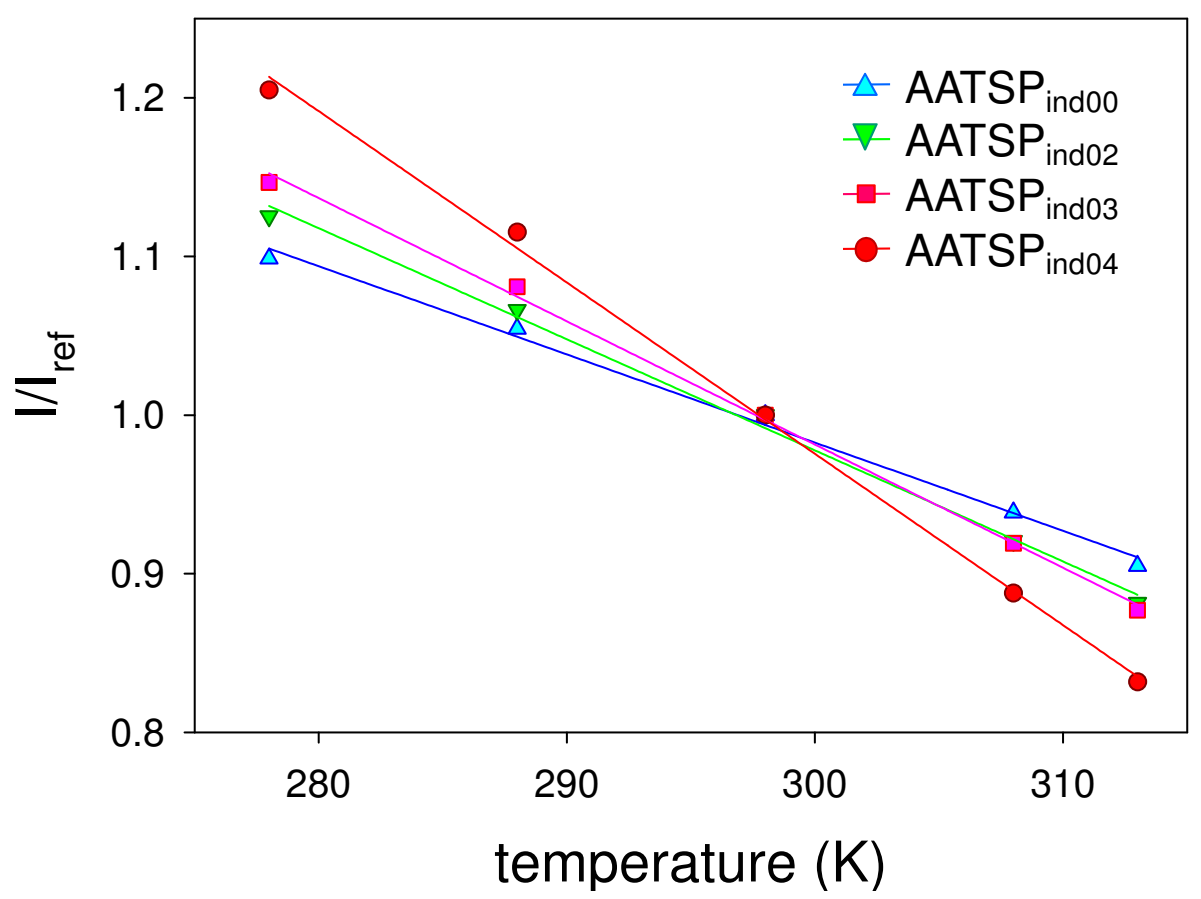

Fig. 6. Temperature calibrations of AATSP ind00, $_{\text {AATSP }}$ ind02, AATSP ind03, $_{\text {, }}$ and AATSP ind04 obtained from the camera system. The reference temperature was $298 \mathrm{~K}$. (Figures obtained from Sakaue et al. [9]) 


\begin{tabular}{ccc} 
AA-TSP & $\begin{array}{c}\text { Temperature Dependency } \\
(\% / \mathrm{K})\end{array}$ & $\begin{array}{c}\text { Signal Level } \\
(\text { normalized })\end{array}$ \\
\hline \hline AATSP $_{\text {ind00 }}$ & -0.6 & 0.87 \\
AATSP $_{\text {ind02 }}$ & -0.7 & 0.65 \\
AATSP $_{\text {ind03 }}$ & -0.8 & 0.73 \\
AATSP $_{\text {ind04 }}$ & -1.1 & 1.00
\end{tabular}

Table 2. Temperature sensitivity and the signal level of AATSP ind00, $_{\text {AATSP }}$ ind02, AATSP ind03, $_{\text {, }}$ and AATSP ${ }_{\text {ind04. }}$ The reference temperature was $298 \mathrm{~K}$ [9]

\subsection{Characterization results: Temperature calibration from $100 \mathrm{~K}$ to $500 \mathrm{~K}$}

Based on the solvent dependency discussed in the previous section, AATSP ind04, which used chloroform as a solvent, was calibrated for a wide temperature range. Fig. 7 shows temperature spectra of $\mathrm{AATSP}_{\text {ind04, }}$, obtained from the spectrometer system. The temperature was varied from a cryogenic temperature of $100 \mathrm{~K}$ up to a high temperature of $500 \mathrm{~K}$. A total

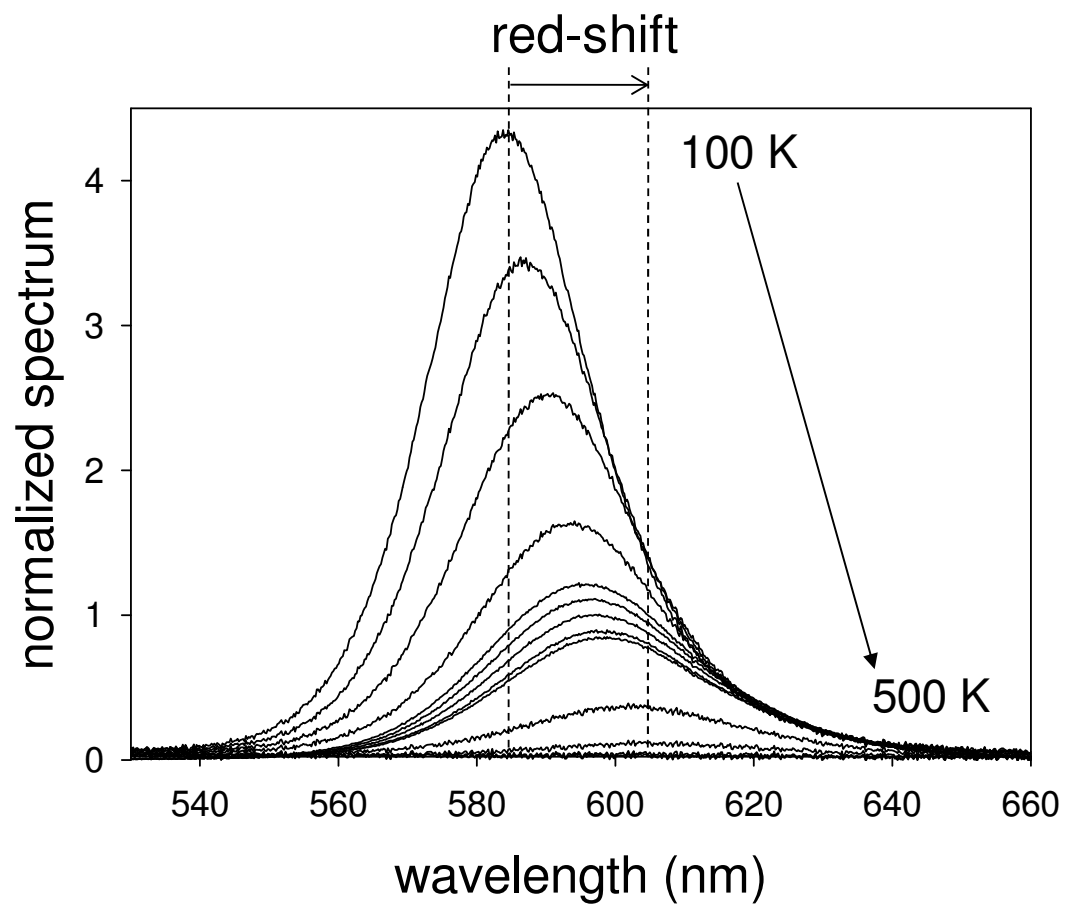

Fig. 7. The temperature spectra of $\mathrm{AATSP}_{\text {ind04 }}$ at temperature ranges from $100 \mathrm{~K}$ to $500 \mathrm{~K}$. Each spectrum was normalized by the luminescent peak at $298 \mathrm{~K}$. Thirteen temperature spectra were measured: 100 K, 150 K, 200 K, 250 K, 278 K, 288 K, 298 K, 308 K, 313 K, 350 K, $400 \mathrm{~K}, 450 \mathrm{~K}$, and $500 \mathrm{~K}$. (Figures obtained from Sakaue et al. [9]) 
of thirteen temperature spectra were measured. Each spectrum was normalized by the luminescent peak at $298 \mathrm{~K}$. As temperatures increased, the luminescent spectra decreased. A red-shift of the luminescent peak occurred with increasing temperature. A maximum change of at least $20 \mathrm{~nm}$ was observed. Luminescent peaks at $450 \mathrm{~K}$ and $500 \mathrm{~K}$ were not clearly identified. Thus, the luminescent peak at $400 \mathrm{~K}$ was used as the maximum red-shift wavelength of AATSP ind04 to determine the peak location.

Fig. 8 shows the temperature calibration of AATSP ind $04_{\text {from }} 100 \mathrm{~K}$ to $500 \mathrm{~K}$, obtained using the camera system. The plot was fitted with a four-parameter sigmoid.

$$
\frac{I}{I_{r e f}}=c_{0}+\frac{c_{1}}{1+\exp \left(-\frac{T-c_{2}}{c_{3}}\right)}
$$

Where $c_{0}, c_{1}, c_{2}$, and $c_{3}$ were calibration constants. The reference temperature was $298 \mathrm{~K}$. The temperature calibration showed a monotonic decrease in luminescent signal with increasing temperature.

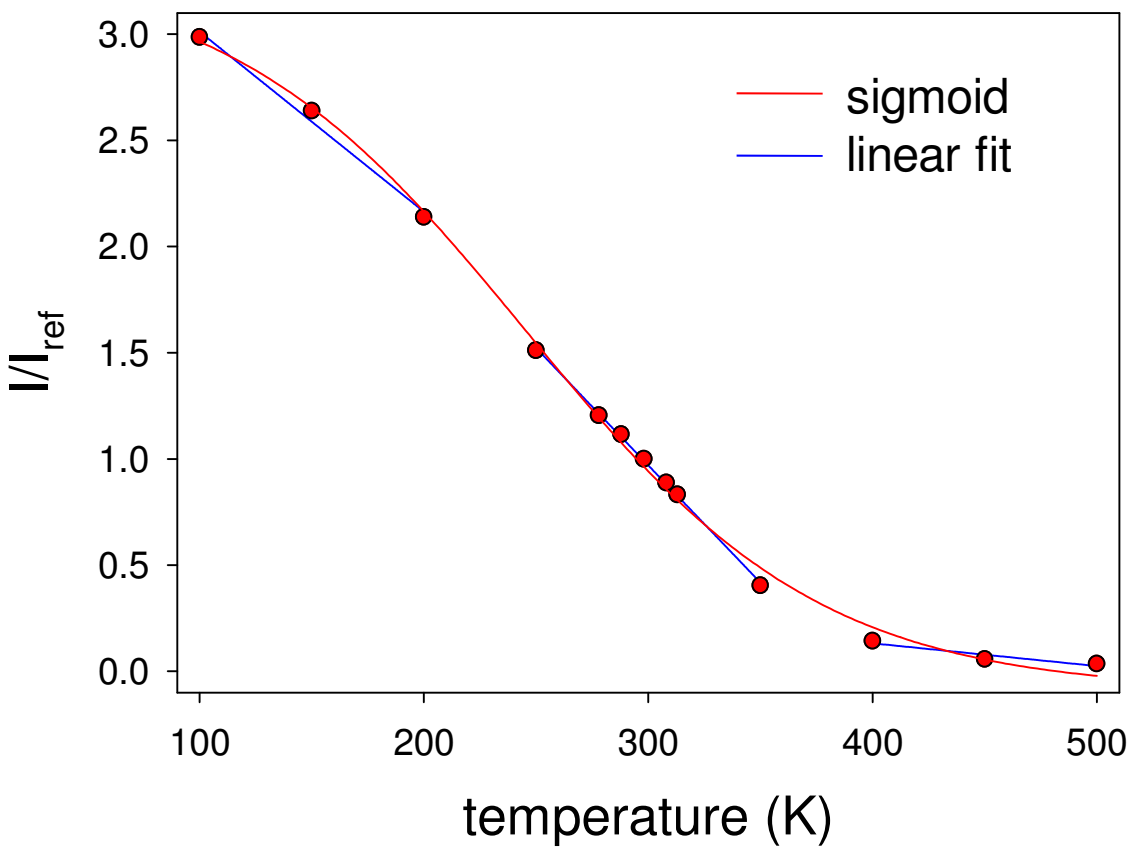

Fig. 8. Temperature calibration of AATSP ind04 $_{\text {at }}$ temperature ranges from 100 to $500 \mathrm{~K}$ obtained from the camera system. The reference temperature was $298 \mathrm{~K}$. A four-parameter sigmoid as well as the first-order polynomial was fitted. The first-order fitting was applied at three temperature regions: low-temperature region from $100 \mathrm{~K}$ to $200 \mathrm{~K}$, middletemperature region from $250 \mathrm{~K}$ to $350 \mathrm{~K}$, and high-temperature region from $400 \mathrm{~K}$ to $500 \mathrm{~K}$. (Figures obtained from Sakaue et al. [9]) 
The first-order fitting of equation (1) was also applied to three temperature regions: a lowtemperature region from $100 \mathrm{~K}$ to $200 \mathrm{~K}$, a middle-temperature region from $250 \mathrm{~K}$ to $350 \mathrm{~K}$, and a high-temperature region from $400 \mathrm{~K}$ to $500 \mathrm{~K}$. These regions are shown in Fig. 7. Although fewer calibration points were used, linear fits gave single $\delta_{T} \mathrm{~S}$ that are useful for engineering application.

Because of the non-linear calibration, $\delta_{T}$ varied with the reference temperature, $T_{r e f}$, for the sigmoidal fitting, which can be derived as a derivative of equation (3) at $T_{\text {ref. }}$. For linear fittings, equation (2) can be used to determine $\delta_{T}$ in the three temperature regions.

$$
\delta_{T}=\left.\frac{d\left(I / I_{r e f}\right)}{d T}\right|_{T=T_{r e f}}=\frac{c_{1}}{c_{3}} \cdot\left(\exp \left(\frac{T_{r e f}-c_{2}}{2 c_{3}}\right)+\exp \left(-\frac{T_{r e f}-c_{2}}{2 c_{3}}\right)\right)^{-2}(\% / \mathrm{K})
$$

Fig. 9 shows $\delta_{T}$ as a function of $T_{r e f}$. It varied with $T_{r e f}$ when the sigmoidal fitting was used. The best $\delta_{T}$ of $-1.3 \% / \mathrm{K}$ could be obtained at a $T_{\text {ref }}$ of $245 \mathrm{~K}$. By using linear fits, three $\delta_{T} \mathrm{~S}$ could be obtained at the low-, the middle-, and the high-temperature regions, respectively. These fittings gave single values of $\delta_{T} \mathrm{~S}$ of $-0.9 \% / \mathrm{K},-1.1 \% / \mathrm{K}$, and $-0.1 \% / \mathrm{K}$, respectively. For a $T_{\text {ref }}$ at $298 \mathrm{~K}$, which was the representative reference temperature, $\delta_{T}$ was $-1.1 \% / \mathrm{K}$ as determined from both fits.

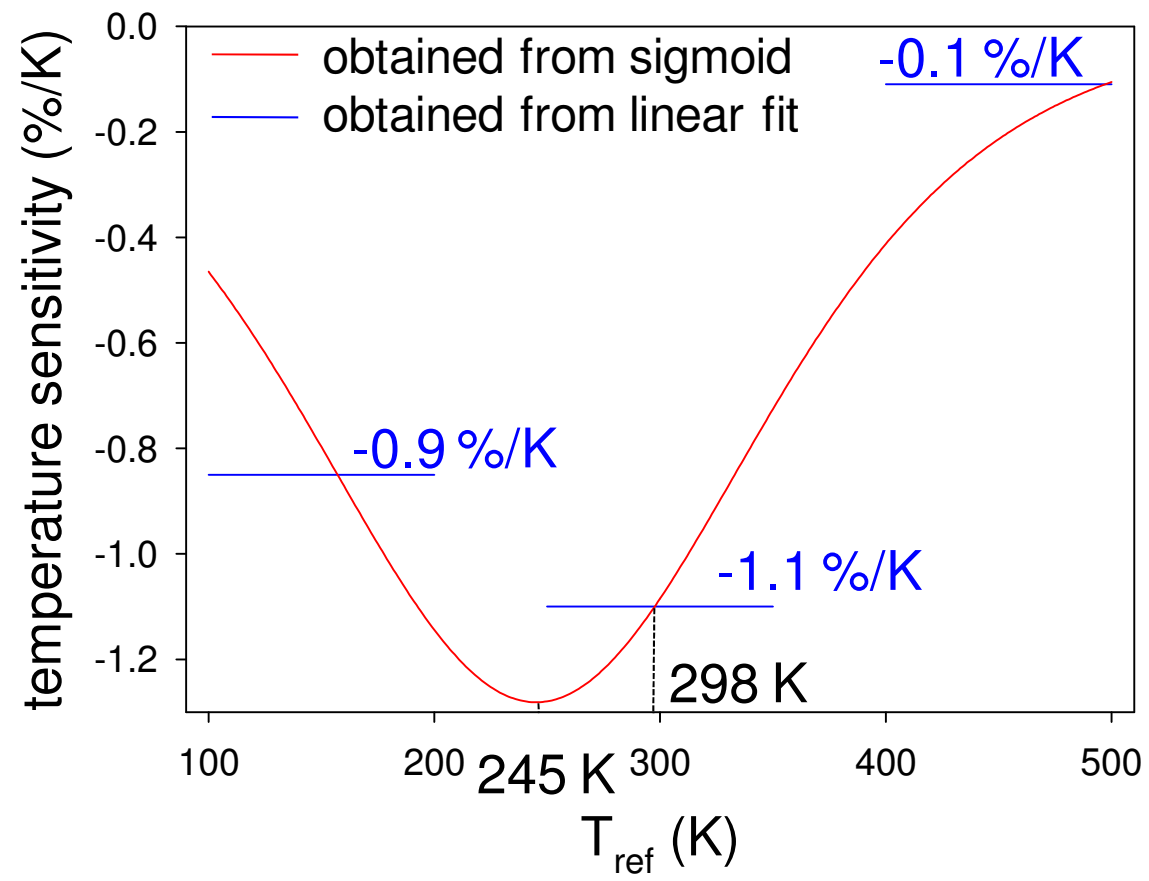

Fig. 9. The temperature sensitivity, $\delta_{T}$, as a function of reference temperature, $T_{\text {ref. }}$ (Figures obtained from Sakaue et al. [9]) 


\subsection{Discussion: Repeatability}

Fig. 10 shows the repeatability of the temperature calibration. Mean values and error bars are shown. The calibration was repeated five times and averaged for each temperature. The standard deviation is shown as an error bar. The temperature calibration showed a relatively large error at cryogenic temperatures, which may be due to the uncertainty of the temperature control of the chamber as well as the hysteresis of our AA-TSP. Because the coating provided a micro-porous structure, which was on the order of ten nanometers in diameter and ten micrometer in depth, the solvent used for dipping deposition tended to remain in the pores. This remaining solvent might have caused the hysteresis at cryogenic temperatures. The calibration results in Figures 6 and 8 are shown as mean values of five repeated calibrations.

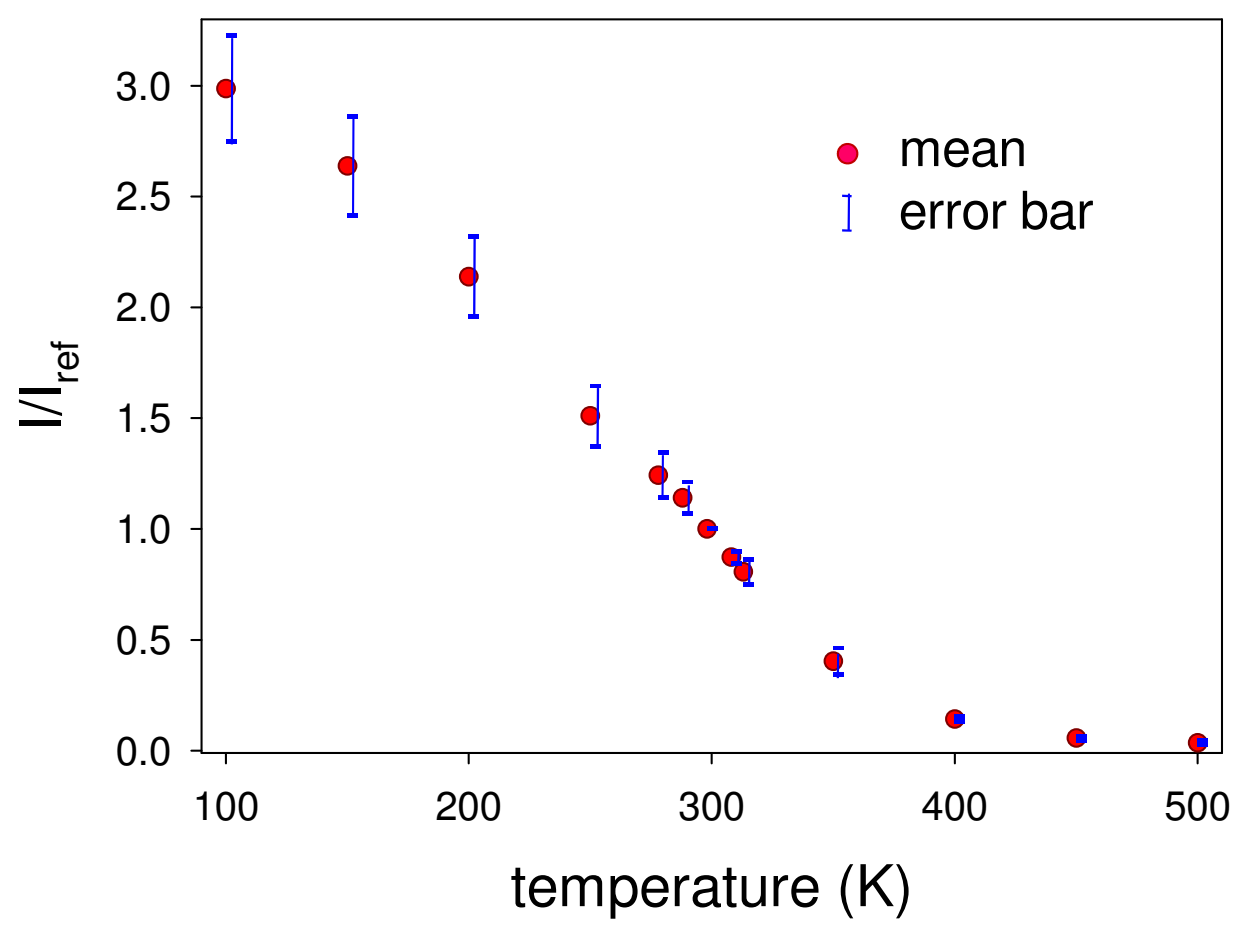

Fig. 10. Repeatability of the temperature calibration obtained from the camera system. Mean values and error bars are shown. Calibrations were repeated five times. (Figures obtained from Sakaue et al. [9]) 


\section{Hypersonic wind tunnel application}

To reveal the aerodynamic heating, hypersonic wind tunnels are used. To apply a TSP to a hypersonic flow, the heating causes a material defects to a conventional TSP, which uses a polymer as a supporting matrix. Because a supporting matrix is aluminum instead of a polymer, we can expect AA-TSP to hold its material properties at higher temperatures as that in the hypersonic application.

\subsection{Compression corner model}

Fig. 11 showed a photograph of wind tunnel model. Referring from Nakakita et al. [11] and Ishiguro et al. [12], a compression corner model was used. It has a $30^{\circ}$ compression corner with its dimension shown in the figure. A thermocouple was used for the temperature measurement, which was placed on the surface of the model. AATSP ind04 $_{\text {was }}$ applied onto the model surface by the dipping deposition method discussed in section 2.1.

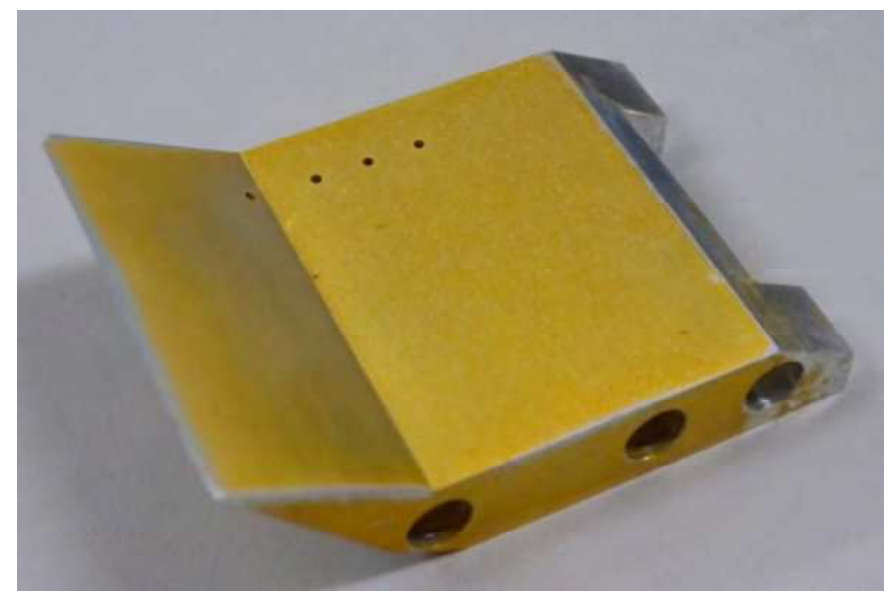

Fig. 11. Photograph of a compression corner model

\subsection{Wind tunnel measurement setup}

Fig. 12 shows a schematic description of The Hypersonic and High Enthalpy Wind Tunnel at The University of Tokyo, Kashiwa Campus. The flow conditions set in our TSP measurements are summarized in Table 3. Fig. 13 shows a schematic description of a model location and an optical setup. A compression corner model was placed in Mach 7.1 flow after the flow stabilization period. We received a signal when placing the model into the test section. This was used to trigger the image acquisition and reference temperature measurement. A model stabilization period is needed after placing the model, which was 2.5 
$\mathrm{s}$. The model was then released from the flow after $6.5 \mathrm{~s}$. Three xenon lamp sources were used to illuminate the AATSP $_{\text {ind04 }}$ coated model. Band-pass filters of $340 \pm 50 \mathrm{~nm}$ were placed in front of the illumination to give UV excitation. A 12-bit high-speed CCD camera (Phantom v12.1) was used to acquire AATSP ind04 images. An optical filter of $620 \pm 50 \mathrm{~nm}$ was placed in front of the camera. Camera frame rate was set at $25 \mathrm{~Hz}$.

\section{Hypersonic and High Enthalpy Wind Tunnel at UT Kashiwa Campus}

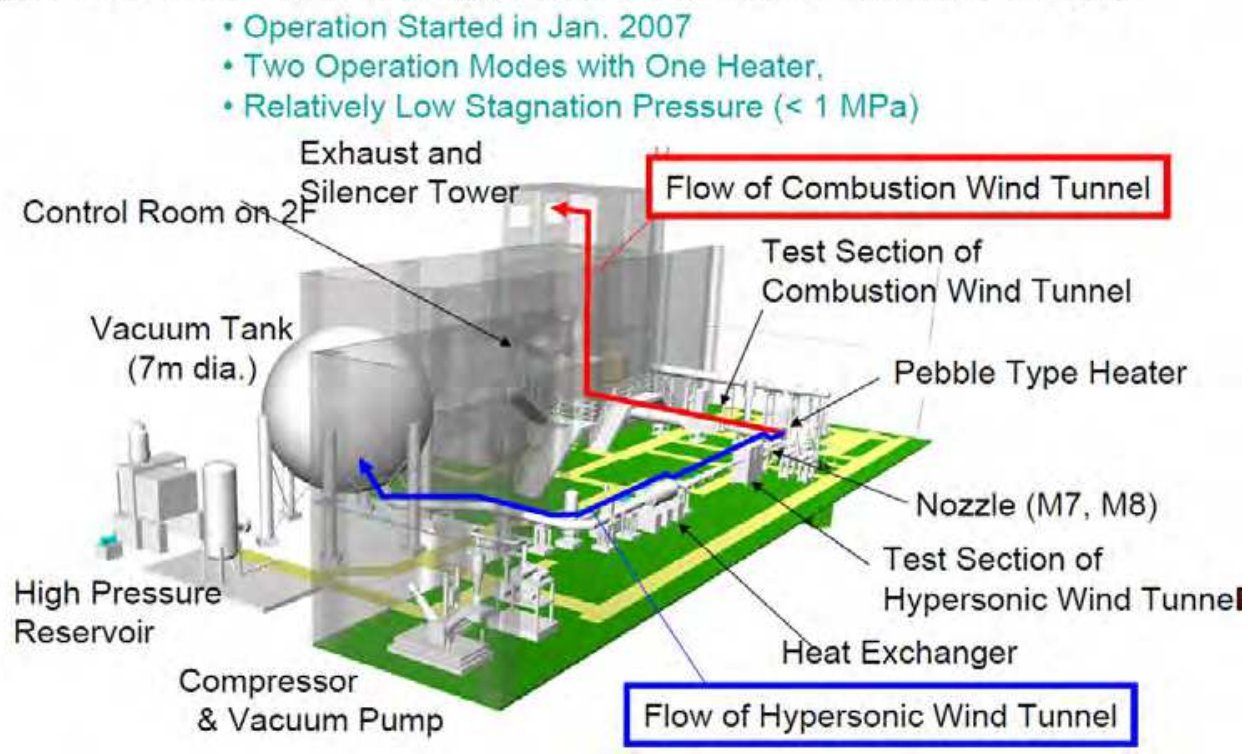

Fig. 12. Schematic description of Hypersonic and High Enthalpy Wind Tunnel at UT Kashiwa. (Figures obtained from http://daedalus.k.u-tokyo.ac.jp/wt/WTpamphE.pdf)

\begin{tabular}{cc}
\hline \hline & conditions \\
\hline mach number & 7.1 \\
stagnation pressure & $0.95 \mathrm{MPa}$ \\
static pressure & $200 \mathrm{~Pa}$ \\
stagnation temperature & $900 \mathrm{~K}$ \\
test duration & $6.5 \mathrm{~s}$ \\
\hline
\end{tabular}

Table 3. Flow conditions of TSP measurement 


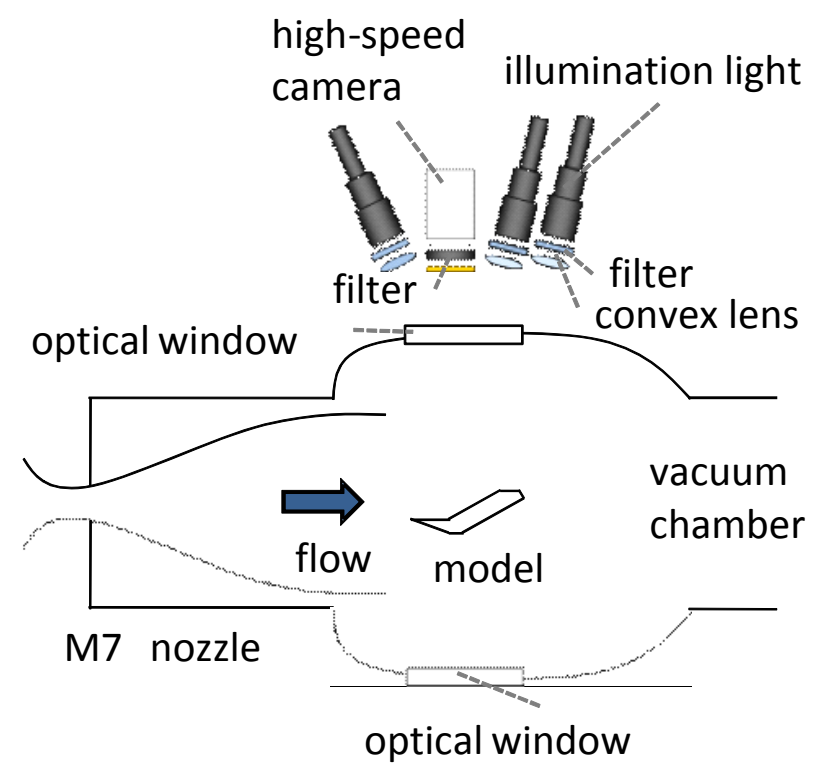

Fig. 13. Schematic of AA-TSP measurement setup

\subsection{Global temperature measurement}

Fig. 14 shows the insitu temperature calibration. Temperature data was monitored from the thermocouple, and the luminescent signal at the corresponding location was related. The

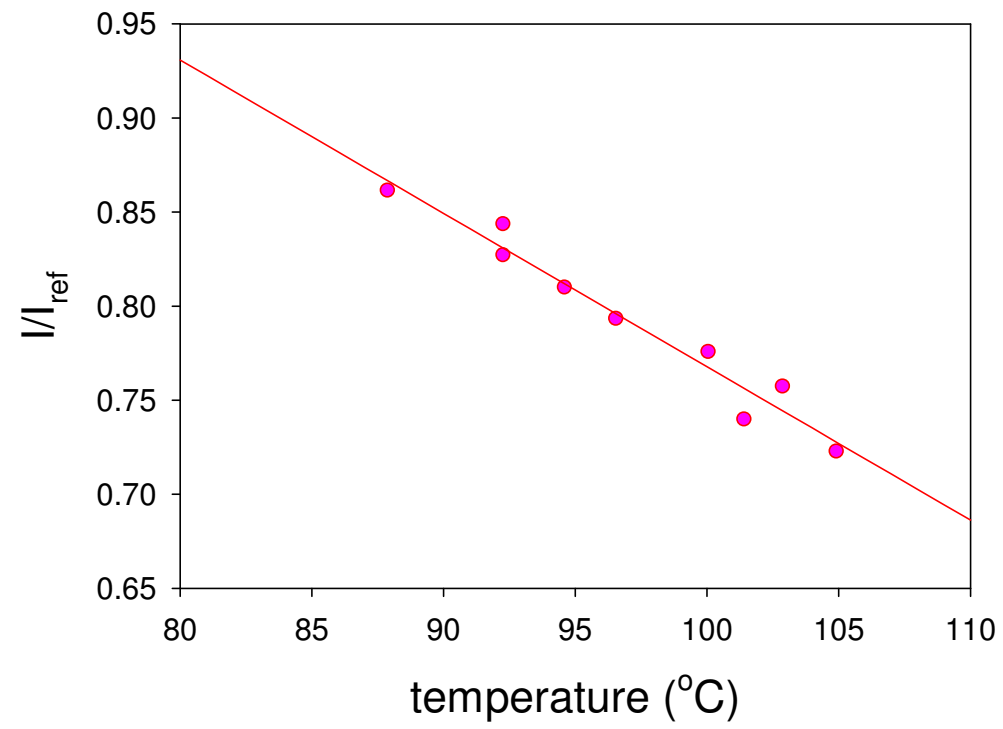

Fig. 14. The insitu temperature calibration. (Figures obtained from Kuriki et al. [10]) 
reference condition was a wind-off condition whose temperature and pressure were $20{ }^{\circ} \mathrm{C}$ and $0.18 \mathrm{kPa}$, respectively. The first order polynomial was used for fitting the calibration points. Based on this calibration, we can convert the luminescent images to the temperature distribution. The temperature sensitivity of the calibration was $-0.82 \% /{ }^{\circ} \mathrm{C}$.

Fig. 15 shows a temperature map and cross sectional distribution obtained from AATSP ind04. Results are shown in every $1 \mathrm{~s}$. We can see that the front edge of the model was heated the most. After $4 \mathrm{~s}$ of the measurement duration, this area was heated up to $413 \mathrm{~K}\left(140{ }^{\circ} \mathrm{C}\right)$.

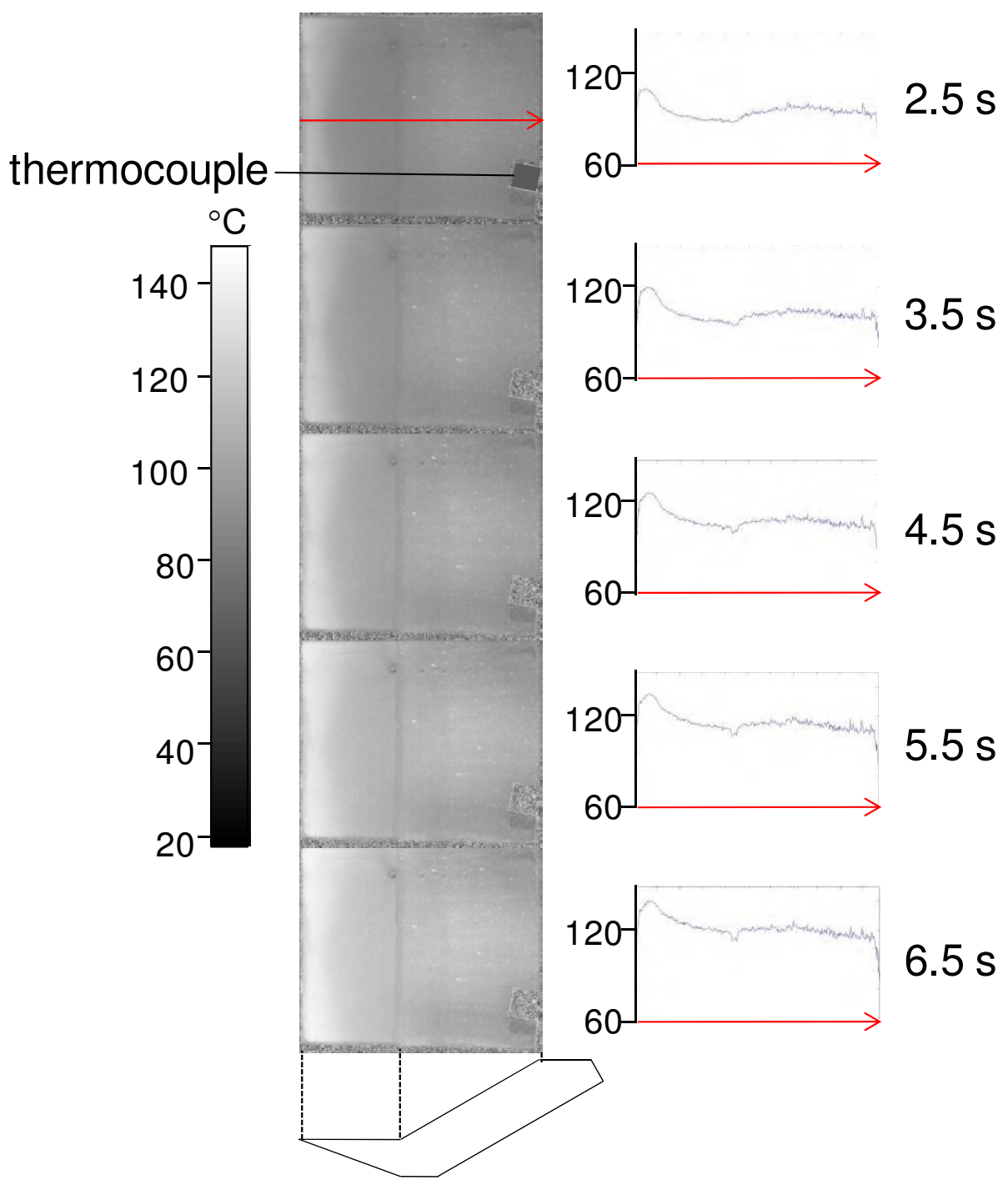

Fig. 15. Temperature map and cross sectional distribution in every $1 \mathrm{~s}$. (Figures obtained from Kuriki et al. [10]) 


\section{Conclusion}

We have developed a quantum dot-based anodized aluminum temperature-sensitive paint for global temperature measurement. Based on the solvent study for applying quantum dots on an anodized aluminum coating, we found that chloroform as a dipping solvent gave the best signal level and temperature sensitivity. The resultant sensor provided temperature sensitivities from $100 \mathrm{~K}$ to $500 \mathrm{~K}$. A total of thirteen temperature points were measured. By using a four-parameter sigmoidal fit to the temperature calibration, the best temperature sensitivity of $-1.3 \% / \mathrm{K}$ was obtained at $245 \mathrm{~K}$. By separating three temperature regions for engineering applications, three constant temperature sensitivities were obtained. The regions were separated into a lowtemperature region of $100 \mathrm{~K}$ to $200 \mathrm{~K}$, a middle- temperature region of $250 \mathrm{~K}$ to $350 \mathrm{~K}$, and a high-temperature region of $400 \mathrm{~K}$ to $500 \mathrm{~K}$. The temperature sensitivities of these regions were $-0.9 \% / \mathrm{K},-1.1 \% / \mathrm{K}$, and $-0.1 \% / \mathrm{K}$, respectively.

The best AA-TSP was used in hypersonic wind tunnel application. It gave the global temperature measurement on a compression corner model at the hypersonic flow of Mach 7.1. The global temperature measurements related to the running time were obtained. The front edge of the model was most heated, and its temperature was raised up to $413 \mathrm{~K}$ for $4 \mathrm{~s}$ of measurement time.

\section{Acknowledgment}

Authors would like to acknowledge Prof. Osamu Imamura at Nihon University, Prof. Kojiro Suzuki, and Mr. Takeo Okunuki at The University of Tokyo for technical supports on The Hypersonic and High Enthalpy Wind Tunnel at The University of Tokyo, Kashiwa Campus.

\section{References}

Bernhard, W. \& Umesh, G. (1981). Polymer Preprints. American Chemical Society, Division of Polymer Chemistry, Vol.22, pp. 308-309

Hines, M. A. \& Guyot-Sionnest, P. (1996). Synthesis and characterization of strongly luminescing ZnS-capped CdSe nanocrystals. J. Phys. Chem., Vol.100, pp. 468-471

Ishiguro, Y; Nagai, H.; Asai, K. \& Nakakita, K. (2007). Visualization of Hypersonic Compression Corner Flows using Temperature- and Pressure-Sensitive Paints. AIAA Paper 2007-118, American Institute for Aeronautics and Astronautics

Kameda, M.; Tabei, T.; Nakakita, K.; Sakaue, H. \& Asai, K. (2005). Image measurement of unsteady pressure fluctuation by a pressure-sensitive coating on porous anodized aluminum. Meas. Sci. Technol., Vol.16, pp. 2517-2524

Kim, J. H; Min, B. R.; Won, J.; Kim, C. K. \& Kang, Y. S. (2004). Journal of Polymer Science, Part B: Polyer Physics, Vol.42, pp. 621-628

Kuriki, K; Sakaue, H.; Imamura, O. \& Suzuki, K. (2010). Temperature-Cancelled AnodizedAluminum Pressure-Sensitive Paint for Hypersonic Compression Corner Flows. AIAA Paper 2010-0673, American Institute for Aeronautics and Astronautics

Liu, T. \& Sullivan, J. P. (2004). Pressure and Temperature Sensitive Paints, Springer, ISBN 3-54022241-3, Heidelberg, Germany (Chapter 1 and Chapter 3) 
Nakakita, K; Yamazaki, T.; Asai, K.; Teduka, N.; Fuji, N. \& Kameda, M. (2000). Pressure Sensitive Paint Measurement in a Hypersonic Shock Tunnel. AIAA Paper 2000-2523, American Institute for Aeronautics and Astronautics

Sakaue, H. (2005). Luminophore application method of anodized aluminum pressure sensitive paint as a fast responding global pressure sensor. Rev. Sci. Instrum., Vol.76, 084101

Sakaue, H.; Aikawa, A. \& Iijima, Y. (2010). Anodized Aluminum as Quantum-Dot Support for Global Temperature Sensing from 100 to 500 Kelvin. Sensors and Actuators B: Chemical, Vol.150, No.2, pp. 569-573

Somayajulu, D. R. S.; Murthy, C. N.; Awasthi, D. K.; Patel, N. V. \& Sarkar, M. (2001). Bulletin of Materials Science, Vol.24, pp. 397-400

Walker, G. W.; Sundar, V. C.; Rudzinski, C. M. \& Wun, A. W. (2003). Quantum-dot optical temperature probes. Appl. Phys. Lett., Vol.83, pp. 3555-3557 


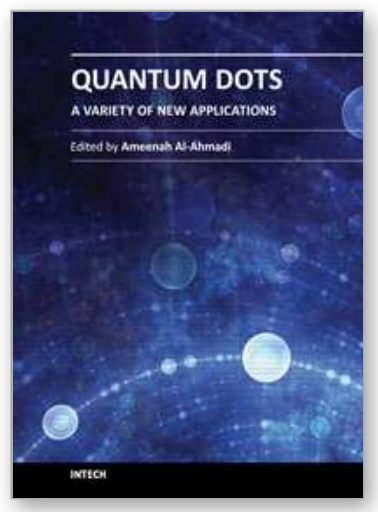

\section{Quantum Dots - A Variety of New Applications}

Edited by Dr. Ameenah Al-Ahmadi

ISBN 978-953-51-0483-4

Hard cover, 280 pages

Publisher InTech

Published online 04, April, 2012

Published in print edition April, 2012

The book "Quantum dots: A variety of a new applications" provides some collections of practical applications of quantum dots. This book is divided into four sections. In section 1 a review of the thermo-optical characterization of CdSe/ZnS core-shell nanocrystal solutions was performed. The Thermal Lens (TL) technique was used, and the thermal self-phase Modulation (TSPM) technique was adopted as the simplest alternative method. Section 2 includes five chapters where novel optical and lasing application are discussed. In section 3 four examples of quantum dot system for different applications in electronics are given. Section 4 provides three examples of using quantum dot system for biological applications. This is a collaborative book sharing and providing fundamental research such as the one conducted in Physics, Chemistry, Biology, Material Science, Medicine with a base text that could serve as a reference in research by presenting up-todate research work on the field of quantum dot systems.

\section{How to reference}

In order to correctly reference this scholarly work, feel free to copy and paste the following:

Hirotaka Sakaue, Akihisa Aikawa, Yoshimi lijima, Takuma Kuriki and Takeshi Miyazaki (2012). Quantum Dots as Global Temperature Measurements, Quantum Dots - A Variety of New Applications, Dr. Ameenah AlAhmadi (Ed.), ISBN: 978-953-51-0483-4, InTech, Available from: http://www.intechopen.com/books/quantumdots-a-variety-of-new-applications/quantum-dots-for-global-temperature-measurements-

\section{INTECH}

open science | open minds

\section{InTech Europe}

University Campus STeP Ri

Slavka Krautzeka 83/A

51000 Rijeka, Croatia

Phone: +385 (51) 770447

Fax: +385 (51) 686166

www.intechopen.com

\section{InTech China}

Unit 405, Office Block, Hotel Equatorial Shanghai

No.65, Yan An Road (West), Shanghai, 200040, China

中国上海市延安西路65号上海国际贵都大饭店办公楼 405 单元

Phone: +86-21-62489820

Fax: $+86-21-62489821$ 
(C) 2012 The Author(s). Licensee IntechOpen. This is an open access article distributed under the terms of the Creative Commons Attribution 3.0 License, which permits unrestricted use, distribution, and reproduction in any medium, provided the original work is properly cited. 